Article

\title{
Impact of Trans-Resveratrol-Sulfates and -Glucuronides on Endothelial Nitric Oxide Synthase Activity, Nitric Oxide Release and Intracellular Reactive Oxygen Species
}

Angela Ladurner ${ }^{1}$, Daniel Schachner ${ }^{1}$, Katharina Schueller ${ }^{2}$, Marc Pignitter ${ }^{2}$, Elke H. Heiss ${ }^{1}$, Veronika Somoza ${ }^{2}$ and Verena M. Dirsch ${ }^{1, *}$

1 Department of Pharmacognosy, University of Vienna, Althanstrasse 14, 1090 Vienna, Austria; E-Mails: angela.ladurner@univie.ac.at (A.L.); daniel.schachner@univie.ac.at (D.S.); elke.heiss@univie.ac.at (E.H.H.)

2 Department of Nutritional and Physiological Chemistry, University of Vienna, Althanstrasse 14, 1090 Vienna, Austria; E-Mails: katharina.schueller@univie.ac.at (K.S.); marc.pignitter@univie.ac.at (M.P.); veronika.somoza@univie.ac.at (V.S.)

* Author to whom correspondence should be addressed; E-Mail: verena.dirsch@univie.ac.at; Tel.: +43-1-4277-55270; Fax: +43-1-4277-55969.

External Editor: Arthur S. Polans

Received: 29 August 2014; in revised form: 30 September 2014 / Accepted: 13 October 2014 / Published: 17 October 2014

\begin{abstract}
Resveratrol (3,5,4'-trihydroxy-trans-stilbene) is a polyphenolic natural product mainly present in grape skin, berries and peanuts. In the vasculature resveratrol is thought to boost endothelial function by increasing endothelial nitric oxide synthase (eNOS) expression, by enhancing eNOS activity, and by reduction of reactive oxygen species (ROS) levels. Recent studies show that dietary resveratrol is metabolized in the liver and intestine into resveratrol-sulfate and -glucuronide derivatives questioning the relevance of multiple reported mechanistic in vitro data on resveratrol. In this study, we compare side by side different physiologically relevant resveratrol metabolites (resveratrol sulfates- and -glucuronides) and their parent compound in their influence on eNOS enzyme activity, endothelial NO release, and intracellular ROS levels. In contrast to resveratrol, none of the tested resveratrol metabolites elevated eNOS enzyme activity and endothelial NO release or affected intracellular ROS levels, leaving the possibility that not tested metabolites are active and able to explain in vivo findings.
\end{abstract}


Keywords: resveratrol metabolites; eNOS; NO; intracellular ROS levels; endothelial cells

\section{Introduction}

Endothelial nitric oxide (NO), the product of the enzyme endothelial nitric oxide synthase (eNOS), is considered a major anti-inflammatory and anti-atherogenic mediator in the cardiovascular system [1]. In particular, the impaired availability of endothelial NO, resulting in endothelial dysfunction, is regarded as the initial step in the development of cardiovascular diseases [2].

The polyphenol resveratrol (3,5,4'-trihydroxy-trans-stilbene), which is found predominantly in grape skin, red wine, berries, and peanuts, is a natural product with well-known favorable effects on endothelial NO availability in the vasculature [3,4]. It has been shown that resveratrol promotes endothelial function by increasing eNOS expression, by enhancing eNOS activity [5]. Resveratrol has been reported to increase endothelial NO release via short and long-term effects. The rapid effect of resveratrol includes the phosphorylation of eNOS by AMPK, or ERK 1 and 2, and the deacetylation of eNOS by SIRT1 [6-9]. Long-term resveratrol increases eNOS mRNA and protein expression [10-13]. Resveratrol supplementation has been shown to be beneficial for endothelial function in several animal models $[14,15]$. However, an increase in eNOS expression upon resveratrol treatment could not be reproduced in vivo $[15,16]$. Apart from its cardiovascular effects, resveratrol supplementation was suggested to be beneficial for combating a wide range of diseases and conditions including inflammatory disorders, cancer, Alzheimer's disease and aging. Multiple cellular targets have been proposed to be responsible for the action of resveratrol $[3,4,12]$.

In the last decades, many studies have been performed to elucidate the mechanism of action of resveratrol, with the aim to combine results obtained from cell culture systems with the data from in vivo observations. However, the relevance of in vitro data for the interpretation of in vivo effects of resveratrol is controversial since the oral bioavailability of resveratrol in vivo is rather limited due to its metabolization to resveratrol sulfates and glucuronides [17-19]. This sparked the issue whether resveratrol is in fact the active molecule in vivo. The oral intake of a dietary relevant dose of $25 \mathrm{mg}$ of resveratrol was reported to lead to a plasma concentration of resveratrol in the nanomolar range, whereas the concentration of metabolites in plasma was in the micromolar range [20]. Additionally, the significant effects of resveratrol in in vivo experiments suggest that some resveratrol metabolites could be biologically relevant [21], either directly or by back conversion to resveratrol in target cells via glucuronidases and sulfatases [22].

Resveratrol metabolites have been reported to elicit a wide range of bioactivities similar to their parent compound resveratrol. For instance, resveratrol-4'-glucuronide, resveratrol-3-glucuronide, and resveratrol-3-sulfate reduced fat accumulation in adipocytes and influenced adipokine expression and secretion. Hence, they may be involved in anti-obesity effects after resveratrol consumption $[23,24]$. Resveratrol-3-sulfate and resveratrol disulfates showed anti-inflammatory activity by counteracting an inflammatory challenge in macrophages [25]. Furthermore, Resveratrol-4'-sulfate inhibited cyclooxygenase-1 and 2 (COX-1 and COX-2) with a potency similar to resveratrol, whereas resveratrol-3-sulfate and resveratrol-3-glucuronide were only weakly active on these enzymes [19]. 
Additionally, resveratrol-3-sulfate and resveratrol-4'-sulfate were able to increase sirtuin-1 activity to the same extent as resveratrol [26]. Sulfate and glucuronide metabolites were reported to inhibit colon cancer cell growth [22,27,28]. Resveratrol metabolites are therefore likely to be involved in the anti-cancer effects of resveratrol.

To interpret and understand results from in vivo studies, it is necessary to identify relevant resveratrol metabolites and to study their mode of action.

In this study, we determine the changes in eNOS activity and endothelial NO release as well as intracellular ROS levels, upon exposure of endothelial cells to several physiological resveratrol metabolites.

\section{Results and Discussion}

\subsection{Impact of Resveratrol and Its Metabolites on eNOS Enzyme Activity}

Since none of the metabolites could so far be identified as the major active compound, it is important to determine the activity of the physiologically relevant metabolites for every function and target, as in this study for the endothelial NO system.

Several in vitro studies reported beneficial effects of resveratrol on the eNOS system in micromolar [8,10,11,29] as well as in nanomolar concentrations [7,13,30]. Micromolar concentrations of resveratrol have been reported to elevate eNOS mRNA levels, activity and expression levels [8,10,11,29]. Additionally, an increase in eNOS expression was observed upon administration of $100 \mathrm{nM}$ resveratrol [13]. A study performed by Klinge et al could demonstrate that nanomolar resveratrol induces ER $\alpha$-Cav-1-c-SRC interaction, resulting in NO production through a Ga-protein-coupled mechanism, suggesting an explanation for the effects seen with resveratrol in vivo [30].

For this study we decided to test resveratrol metabolites in micromolar concentrations since oral administration of $5 \mathrm{~g}$ of resveratrol led to a plasma concentration of metabolites in this concentration range [31]. The parent compound resveratrol itself was used in the same concentrations as previously as a control [10,29], although most likely physiologically not relevant.

It has been previously reported that resveratrol is able to enhance eNOS activity, among others, by stimulation of eNOS expression. This is achieved via stabilization of eNOS mRNA and direct increase in eNOS gene transcription [10]. Since effects on gene transcription are rather slow, we determined eNOS enzyme activity and endothelial NO release $24 \mathrm{~h}$ after treating endothelial EA.hy 926 cells with resveratrol or resveratrol metabolites (Figure 1).

In a first experiment the $\left[{ }^{14} \mathrm{C}\right] \mathrm{L}$-arginine $/\left[{ }^{14} \mathrm{C}\right] \mathrm{L}$-citrulline conversion assay was utilized to measure eNOS enzyme activity (Figure 2). Treatment of endothelial cells with resveratrol concentration-dependently increased eNOS enzyme activity up to 1.64 fold at $100 \mu \mathrm{M}$ compared to control conditions, thereby confirming the previously reported eNOS stimulation by resveratrol [10]. As resveratrol is metabolized in vivo, we studied the effect of metabolites on eNOS activity. We used resveratrol-3-sulfate, resveratrol-4'-sulfate, resveratrol disulfates, resveratrol-3-glucuronide and resveratrol-4'-glucuronide in concentrations from 1 to $100 \mu \mathrm{M}$ in the same assay. However, none of the tested resveratrol sulfate or glucuronide metabolites was able to elicit a significant change in eNOS enzyme activity. 
Figure 1. Synthesis of resveratrol glucuronides (A) and sulfates (B).

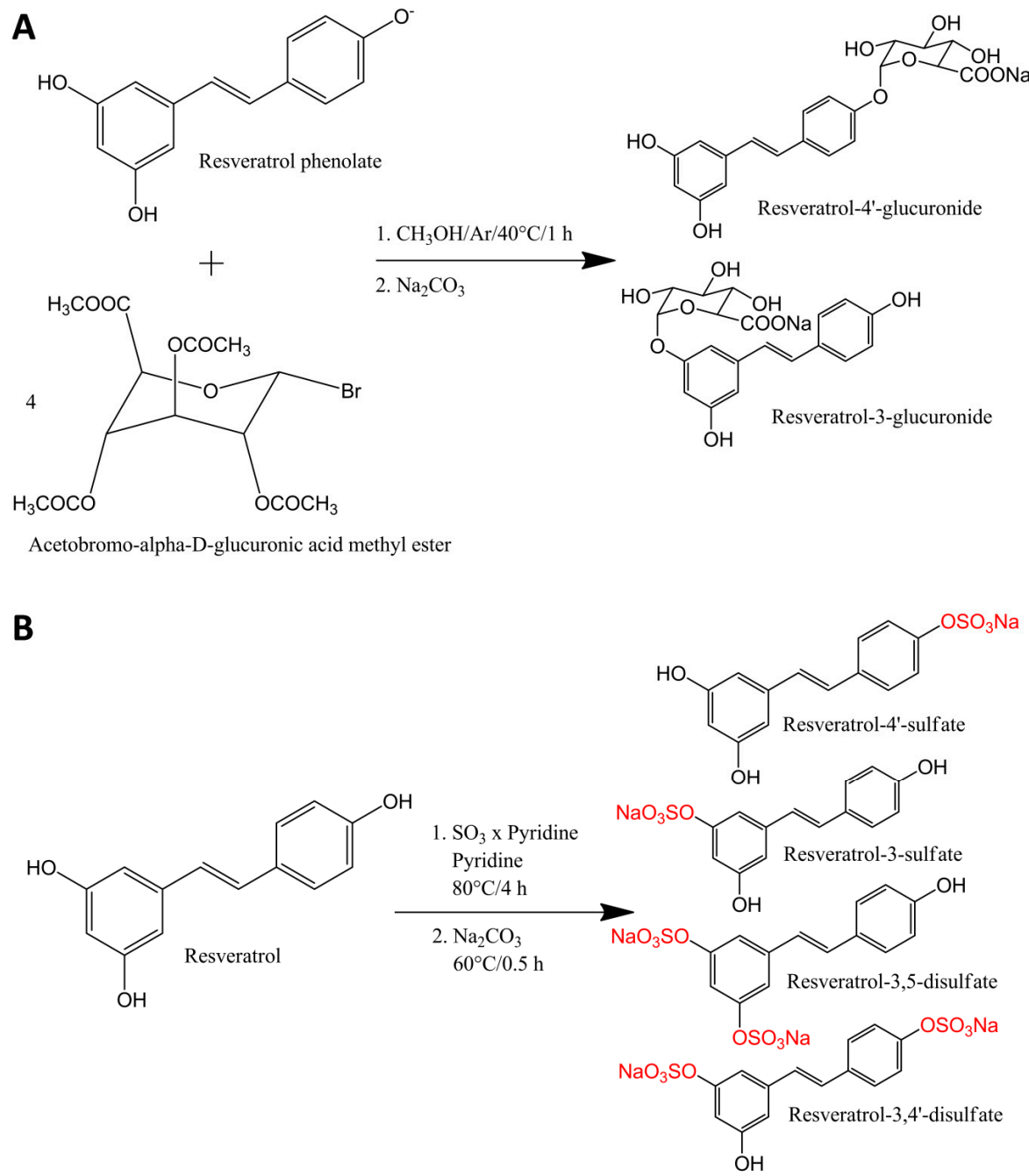

Figure 2. Influence of resveratrol and its metabolites on eNOS enzyme activity. EA.hy926 cells were treated with the indicated concentrations of resveratrol or its metabolites for $24 \mathrm{~h}$. Then an $\left[{ }^{14} \mathrm{C}\right] \mathrm{L}$-arginine/ $\left[{ }^{14} \mathrm{C}\right] \mathrm{L}$-citrulline conversion assay was performed as described. $\left[{ }^{14} \mathrm{C}\right] \mathrm{L}$-citrulline production was normalized to the untreated control $(* * * p<0.001$; mean $\pm \mathrm{SD}$, $n=3)$.

Resveratrol

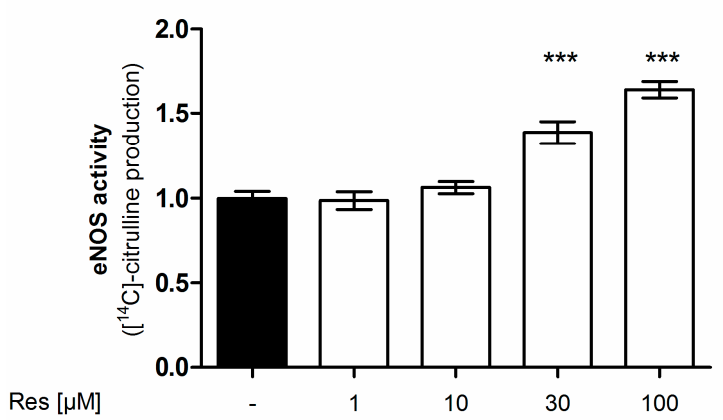

Resveratrol-4'-sulfate

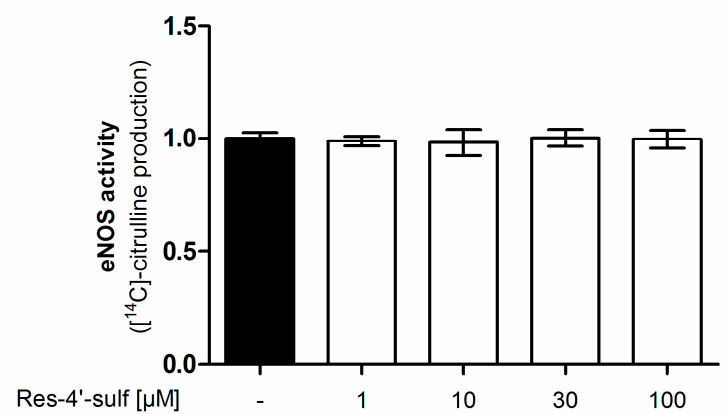


Figure 2. Cont.
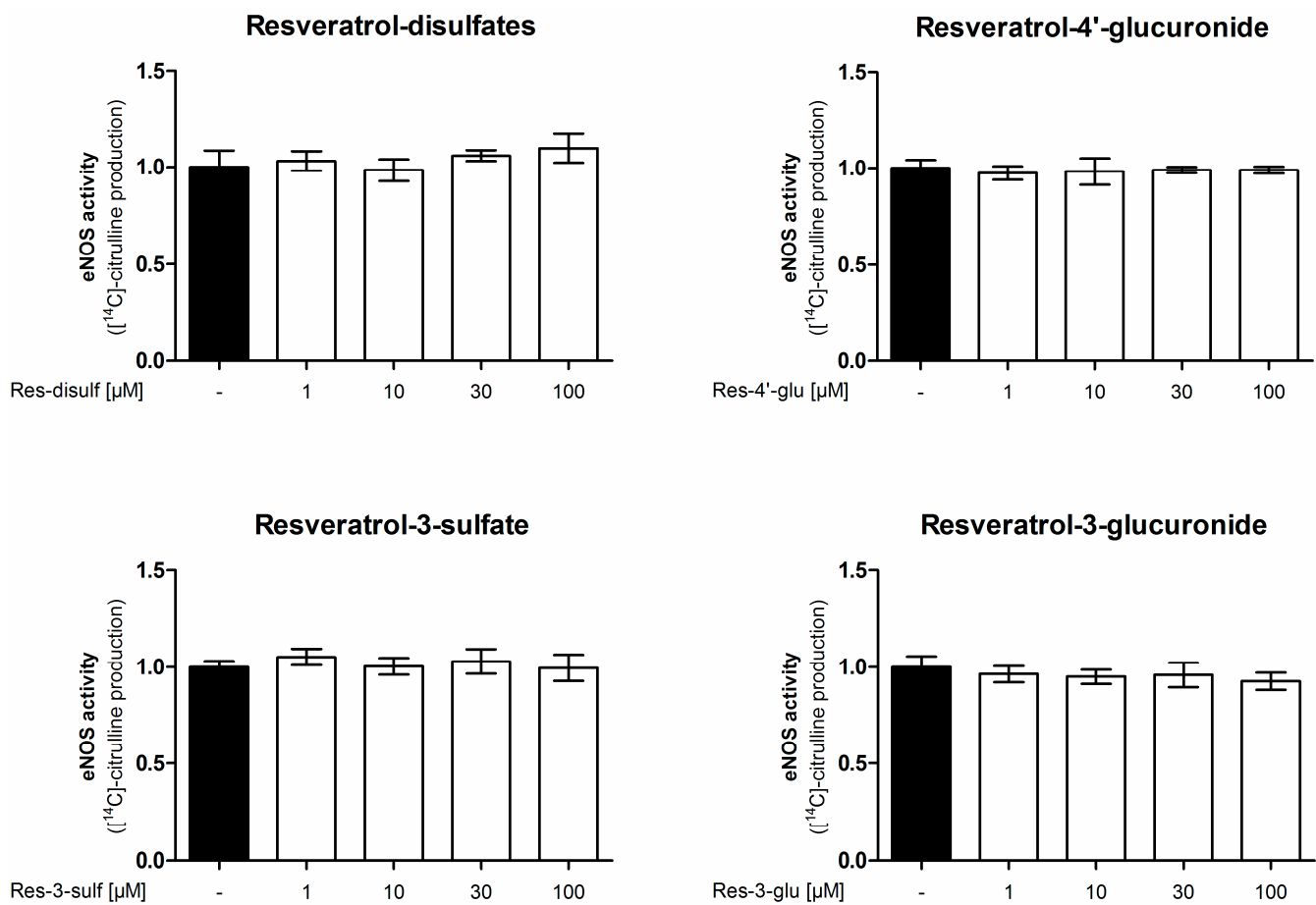

To demonstrate that $\left[{ }^{14} \mathrm{C}\right] \mathrm{L}$-citrulline production upon resveratrol treatment derives from eNOS enzyme activity the experiment was repeated in the presence of the NOS-inhibitor L-NAA ( $\mathrm{N}^{\mathrm{G}}$-Amino-L-arginine hydrochloride) (Figure 3). L-NAA reduced the basal and completely blocked the resveratrol-enhanced arginine conversion thereby confirming the NOS-specificity of the resveratrol effect.

Figure 3. Influence of the NOS inhibitor L-NAA on the effect of resveratrol on eNOS enzyme activity. EA.hy926 cells were treated with the indicated concentrations of resveratrol for $24 \mathrm{~h}$. Then an $\left[{ }^{14} \mathrm{C}\right] \mathrm{L}$-arginine/ $\left[{ }^{14} \mathrm{C}\right] \mathrm{L}$-citrulline conversion assay was performed as described both in the presence and absence of the NOS inhibitor L-NAA. $\left[{ }^{14} \mathrm{C}\right] \mathrm{L}$-citrulline production was normalized to the untreated control (***p $<0.001$; mean $\pm \mathrm{SD}, n=3)$.

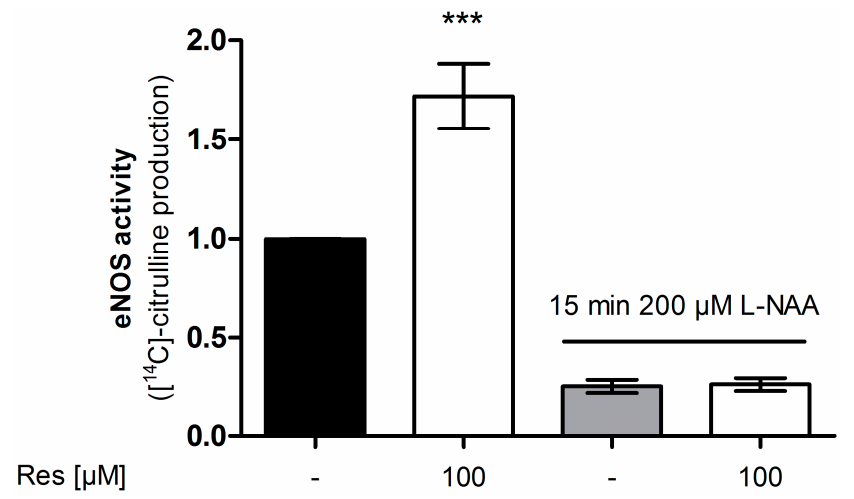

\subsection{Impact of Resveratrol and Its Metabolites on Endothelial NO Release}

It is possible that the tested resveratrol metabolites are not directly changing eNOS enzyme activity but enhance the bioavailability of endothelial NO for example through the inhibition of superoxide-mediated NO inactivation [5]. Therefore, we determined the levels of endothelial NO release 
in EA.hy926 cells after treatment with resveratrol or resveratrol sulfate or glucuronide conjugates for $24 \mathrm{~h}$ (Figure 4). Resveratrol concentration-dependently increased endothelial NO release reaching significance and displaying a 5-fold increase at $30 \mu \mathrm{M}$. However, none of the tested resveratrol sulfate or glucuronide metabolites was able to elicit a significant change in endothelial NO release.

Figure 4. Influence of resveratrol and its metabolites on endothelial NO release. EA.hy926 cells were treated with the indicated concentrations of compounds for $24 \mathrm{~h}$. Endothelial NO release was measured by incubation with the NO-sensitive fluorescent probe diaminofluorescein-FM. Fluorescence values were normalized to the number of viable cells as determined by resazurin staining (** $p<0.01$; mean $\pm \mathrm{SD}, n=3$ ).

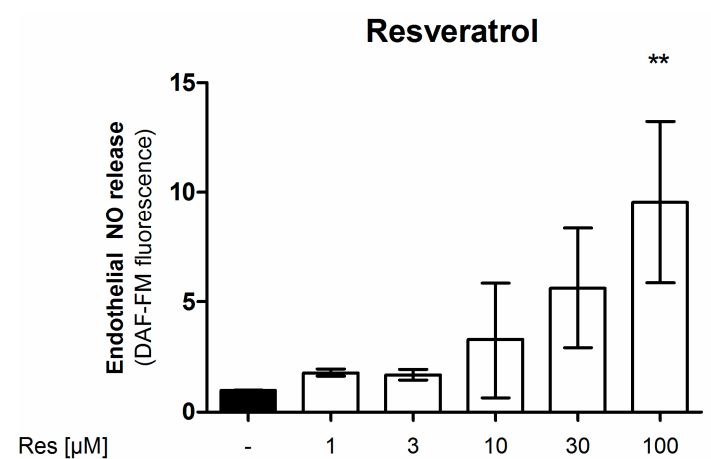

Resveratrol disulfates
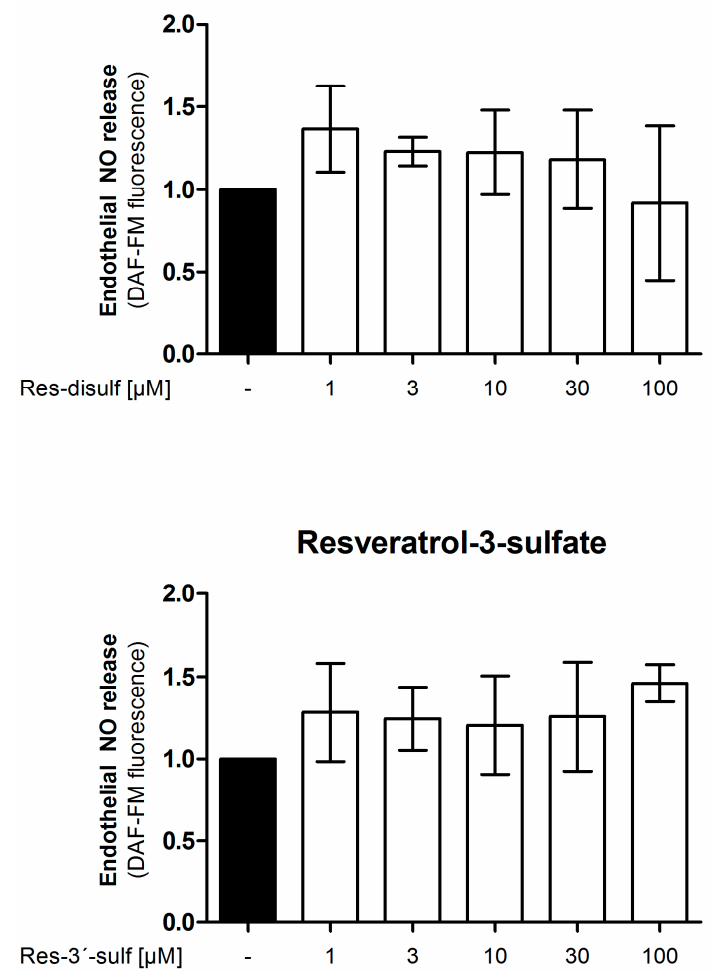
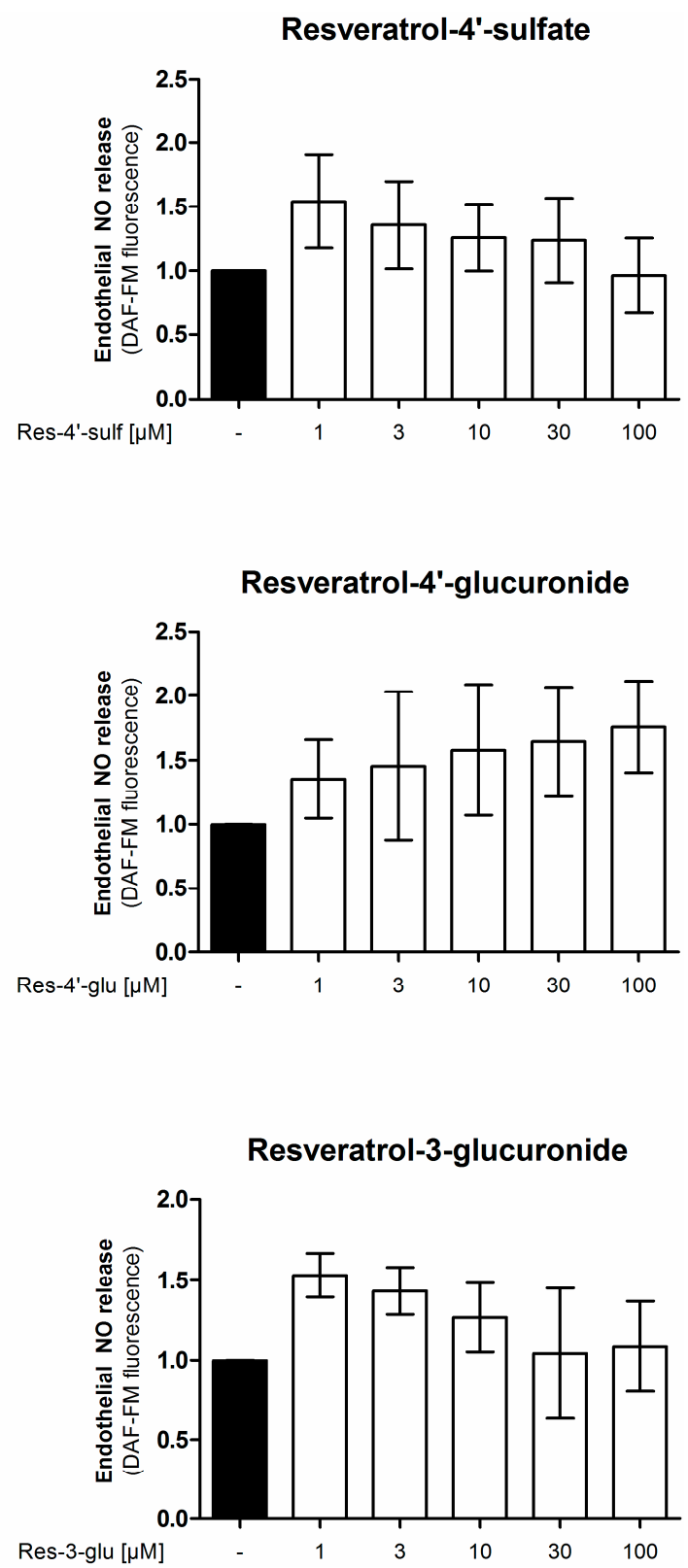

2.3. Impact of Resveratrol and Its Metabolites on Intracellular Reactive Oxygen Species (ROS) Levels

Increased ROS levels have been found to be a major contributor to the development of cardiovascular diseases. Resveratrol is well-known to reduce ROS levels in endothelial cells. It not only directly scavenges 
ROS [32], but also activates expression of antioxidant enzymes such as superoxide dismutase 1, glutathione peroxidase or thioredoxin $[33,34]$. Under certain conditions resveratrol can, however, elicit pro-oxidant effects on the endothelium, suggesting a dual role of resveratrol in endothelial cells $[35,36]$. In a recent study $10 \mu \mathrm{M}$ doses of resveratrol were shown to exert pro-oxidant effects whereas concentrations as low as $0.5 \mu \mathrm{M}$ had an opposite effect [35]. Apart from the applied doses, the oxidative state of the cells seems to be important. Resveratrol has been shown to act as a pro-oxidant under low oxidative conditions and turning into an antioxidant under strong oxidative conditions [37].

To elucidate if the tested resveratrol metabolites affect the cellular ROS detoxification systems, we investigated their effect on intracellular ROS levels. We treated EA.hy926 cells with resveratrol or resveratrol sulfate or glucuronide derivatives for $24 \mathrm{~h}$ and determined their ROS load by DCF staining (Figure 5). However, apart from the parent compound resveratrol none of the tested resveratrol metabolites was able to significantly change intracellular ROS levels. The fact that resveratrol, starting at $30 \mu \mathrm{M}$, increased intracellular ROS levels is in agreement with an already published study [35].

Figure 5. Influence of resveratrol and its metabolites on intracellular reactive oxygen species levels. EA.hy926 cells were treated with the indicated concentrations of resveratrol or its metabolites for $24 \mathrm{~h}$. Intracellular ROS was measured by incubation with the fluorescent probe 2',7'-dichloro-fluorescein-diacetate (DCF). (** $p<0.01$, $* * * p<0.001$; mean $\pm \mathrm{SD}, n=4$ ).
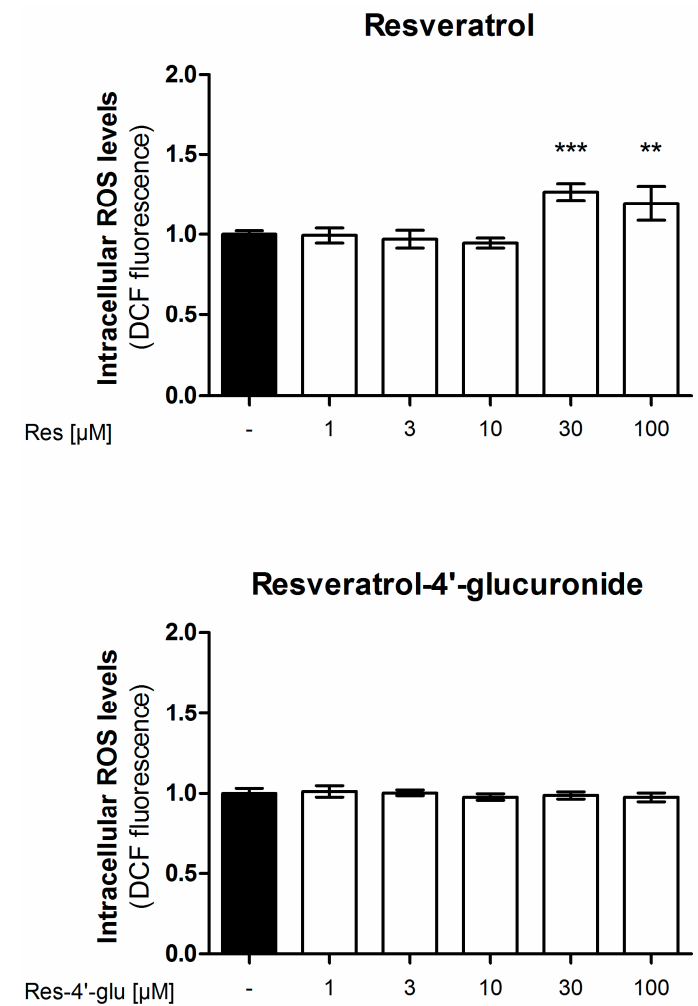
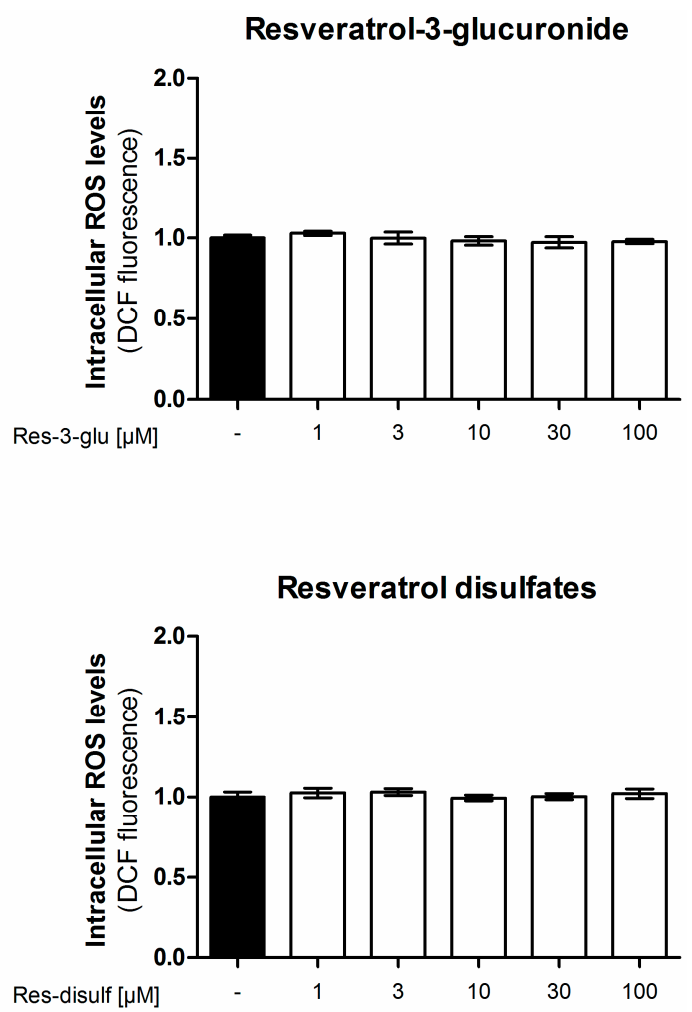

\section{Experimental Section}

\subsection{Chemicals and Cell Culture Reagents}

Dulbecco's modified Eagle's medium (DMEM) without phenol red containing $4.5 \mathrm{~g} / \mathrm{L}$ glucose, glutamine, benzylpenicillin and streptomycin were purchased from Lonza (Verviers, Belgium), HAT 
supplement (100 $\mu \mathrm{M}$ hypoxanthine, $0.4 \mu \mathrm{M}$ aminopterin and $16 \mu \mathrm{M}$ thymidine) from Biochrom (Berlin, Germany), and trypsin from Cambrex (Verviers, Belgium). Fetal bovine serum (FBS) was obtained from Gibco via Invitrogen (Paisley, UK). A23187 were bought from Alexis Biochemicals (Lausen, Switzerland) and [14C]L-arginine (346 mCi/mmol) from New England Nuclear (Boston, MA, USA). $\mathrm{N}^{\mathrm{G}}$-Amino-L-arginine (hydrochloride) (L-NAA) was obtained from Cayman Chemicals via Biomol (Hamburg, Germany). All other chemicals, including trans-resveratrol, were bought from Sigma-Aldrich (Vienna, Austria). TLC plates were bought from Machery-Nagel (Markus Bruckner Analysentechnik, Linz, Austria).

\subsection{Synthesis and Purification of Resveratrol Conjugates}

Synthesis of resveratrol glucuronides (Figure 1A) was performed as described previously [18]. Synthesis and purification of resveratrol sulfates (Figure 1B) were modified according to Wenzel et al. [18]. Briefly, $4 \mathrm{mmol}$ trans-resveratrol and $8 \mathrm{mmol}$ sulfur trioxide pyridine complex were separately dissolved in anhydrous pyridine. The reaction was started by slowly adding resveratrol to sulfur trioxide pyridine complex. The mixture was kept under nitrogen atmosphere and was heated up to $80{ }^{\circ} \mathrm{C}$ under reflux for $4 \mathrm{~h}$. To convert the synthesis products into sodium salts, $160 \mathrm{mmol} \mathrm{Na}_{2} \mathrm{CO}_{3}$ was added to the mixture and stirred at $60{ }^{\circ} \mathrm{C}$ for another $30 \mathrm{~min}$. Prior to purification of the resveratrol sulfates, the solvent was removed by rotary evaporation. The purification of the resveratrol sulfates was performed by a Dionex Ultimate 3000 semi-preparative LC system (Thermo Fisher Scientific, Vienna, Austria) equipped with a UV detector set to $300 \mathrm{~nm}$. The resveratrol sulfates were separated at a flow of $2.5 \mathrm{~mL} / \mathrm{min}$ on a RP18 column (Synergi Fusion, $250 \times 10 \mathrm{~mm}, 4 \mu \mathrm{m}$, Phenomenex, Aschaffenburg, Germany) using a methanol gradient. The gradient started with 3\% methanol and 97\% ammonium formate $(10 \mathrm{mM}, \mathrm{pH} 8.2)$ and reached $75 \%$ methanol after $45 \mathrm{~min}$ before $100 \%$ methanol was reached after another $2 \mathrm{~min}$. To separate resveratrol-3-sulfate from resveratrol-4'-sulfate, the corresponding fraction from the first purification was further purified using the same column and mobile phase. The second purification step started with $25 \%$ methanol, which was kept constant for $35 \mathrm{~min}$, and ended with 100\% methanol after $40 \mathrm{~min}$. After structure identification, purities of $91.5 \%, 98.4 \%$ and $98.6 \%$, for resveratrol-3-sulfate, resveratrol-4'-sulfate and resveratrol disulfates (resveratrol-3,4'-disulfate:resveratrol-3,5-disulfate, 1:1) were determined by means of LCMS(+) and 2D-NMR, as described earlier [18].

\subsection{Cell Culture}

The human endothelial cell line EA.hy926 (kindly provided by Dr. C.-J.S. Edgell, University of North Carolina, Chapel Hill, NC, USA) [38] was grown in DMEM (without phenol red) supplemented with $2 \mathrm{mM}$ glutamine, $100 \mathrm{U} / \mathrm{mL}$ benzylpenicillin, $100 \mu \mathrm{g} / \mathrm{mL}$ streptomycin, HAT supplement, and 10\% FBS up to passage 26 . Resveratrol and resveratrol metabolites were dissolved in dimethyl sulfoxide (DMSO) and stored at $-80{ }^{\circ} \mathrm{C}$. Final DMSO concentrations did not exceed $0.1 \%$. Control cells were always treated with an equal volume of solvent. 


\section{4. $\left[{ }^{14} \mathrm{C}\right] \mathrm{L}$-Arginine/ $\left[{ }^{14} \mathrm{C}\right] \mathrm{L}$-Citrulline Conversion Assay}

The enzymatic reaction catalyzed by eNOS converts the amino acid arginine into citrulline and NO. $\left[{ }^{14} \mathrm{C}\right] \mathrm{L}$-citrulline production can thus serve as a surrogate marker of NO production. The assay was performed as previously described [39]. In short, EA.hy926 cells were seeded in six-well plates at a density of $5 \times 10^{5}$ cells/well and treated with test compounds at confluence, after approximately $72 \mathrm{~h}$. Then the endothelial cells were equilibrated in HEPES buffer (HEPES $10 \mathrm{mM}, \mathrm{NaCl} 145 \mathrm{mM}, \mathrm{KCl} 5 \mathrm{mM}$, $\mathrm{MgSO}_{4} 2 \mathrm{mM}, \alpha-\mathrm{D}(+)-$ Glucose $\left.10 \mathrm{mM}, \mathrm{CaCl}_{2} \times 2 \mathrm{H}_{2} \mathrm{O} 1.5 \mathrm{mM}, \mathrm{pH} 7.4\right)$ for $10 \mathrm{~min}$ at $37^{\circ} \mathrm{C}$. In some experiments $200 \mu \mathrm{M}$ of the irreversible eNOS inhibitor $\mathrm{N}^{\mathrm{G}}$-Amino-L-arginine (hydrochloride) (L-NAA) was added and the buffer was replaced after $15 \mathrm{~min}$. Subsequently, $0.32 \mu \mathrm{M}\left[{ }^{14} \mathrm{C}\right] \mathrm{L}$-arginine $(346 \mathrm{mCi} / \mathrm{mmol})$ and $1 \mu \mathrm{M}$ of the calcium ionophore A23187 were added for $15 \mathrm{~min}$. The reaction was stopped by lysing cells, followed by extraction with ethanol and ethanol/water. The extracts were dried under vacuum (SPD 1010 SpeedVac, Thermo Savant, Thermo Scientific, Langenselbold, Germany) and resolved in water/methanol (1:1). After separation of $\left[{ }^{14} \mathrm{C}\right] \mathrm{L}$-arginine from $\left[{ }^{14} \mathrm{C}\right] \mathrm{L}$-citrulline by thin layer chromatography (Polygram SIL N-HR, Machery-Nagel, Austria) in the solvent system water:chloroform:methanol:ammonium hydroxide 25\% (2:1:9:4, v/v/v/v), [ $\left.{ }^{14} \mathrm{C}\right] \mathrm{L}-$ citrulline was quantified by autoradiography in a phosphoimager (BAS-1800II, Fujifilm, Düsseldorf, Germany). AIDA software (raytest, Langenzersdorf, Austria) was used for densitometric analysis.

\subsection{Quantification of NO Release by Diaminofluorescein-FM (DAF-FM)}

Quantification of NO released from endothelial cells was performed using diaminofluorescein-FM (DAF-FM), a NO-sensitive fluorescent probe. EA.hy926 cells were seeded in 96-well plates at a density of $2.5 \times 10^{4}$ cells/well and were treated with test compounds at confluence after approximately $72 \mathrm{~h}$. Cells were washed two times with PBS + $\left(137 \mathrm{mM} \mathrm{NaCl}, 2.68 \mathrm{mM} \mathrm{KCl}, 8.1 \mathrm{mM} \mathrm{Na} 2 \mathrm{HPO}_{4}, 1.47 \mathrm{mM}\right.$ $\left.\mathrm{KH}_{2} \mathrm{PO}_{4}, 0.5 \mathrm{mM} \mathrm{MgCl}_{2} \times 6 \mathrm{H}_{2} \mathrm{O}, 0.68 \mathrm{mM} \mathrm{CaCl}_{2} \times 2 \mathrm{H}_{2} \mathrm{O}\right)$ containing $100 \mu \mathrm{M}$ arginine and equilibrated $10 \mathrm{~min}$ in this buffer. Then, A23187 was added to a final concentration of $1 \mu \mathrm{M}$ and DAF-2 to a final concentration of $0.1 \mu \mathrm{M}$, and the cells were incubated for $1 \mathrm{~h}$ at $37{ }^{\circ} \mathrm{C}$. Addition of L-NAME to a final concentration of $200 \mu \mathrm{M}$ allowed correction for non-NO-specific fluorescence. The supernatant was transferred to a black 96-well plate and fluorescence was measured in a plate reader (Genios Pro, Tecan, Grödig, Austria) with an excitation wavelength of $485 \mathrm{~nm}$ and an emission wavelength of $520 \mathrm{~nm}$. Fluorescence values were normalized to viable cells as determined by resazurin conversion method [40]. For this, the cells were incubated with $0.1 \mathrm{mg} / \mathrm{mL}$ resazurin in PBS for $30 \mathrm{~min}$ before measuring the fluorescence in a plate reader (Genios Pro, Tecan, Grödig, Austria) at an excitation wavelength of $535 \mathrm{~nm}$ and an emission wavelength of $590 \mathrm{~nm}$.

\subsection{Measurement of Intracellular Reactive Oxygen Species (ROS) Levels}

Intracellular ROS levels were measured with the 2',7'-dichloro-fluorescein-diacetate (DCF) probe. EA.hy926 cells were seeded in 12-well plates at a density of $1.6 \times 10^{5}$ cells/well and were treated with test compounds at confluence after approximately $72 \mathrm{~h}$. Catalase (activity $21600 \mathrm{U} / \mathrm{mg}$ protein) was added to the cell culture medium at $50 \mathrm{U} / \mathrm{mL}$ and co-incubated with the test substances to inhibit formation of ROS in the cell culture supernatant [41]. After $24 \mathrm{~h}$ treatment, cells were washed once with 
HBSS (140 mM NaCl, $5 \mathrm{mM} \mathrm{KCl,} 0.14 \mathrm{mM} \mathrm{Na}_{2} \mathrm{HPO}_{4}, 0.37 \mathrm{mM} \mathrm{KH}_{2} \mathrm{PO}_{4}, 0.80 \mathrm{mM} \mathrm{MgSO} 4,1.2 \mathrm{mM}$ $\mathrm{CaCl}_{2} \times 2 \mathrm{H}_{2} \mathrm{O}, 5.6 \mathrm{mM}$ glucose, $20 \mathrm{mM}$ HEPES) and incubated with $20 \mu \mathrm{M}$ DCF in HBSS for $25 \mathrm{~min}$ at $37{ }^{\circ} \mathrm{C}$. After washing the cells once with HBSS, cells were trypsinized and resuspended in PBS containing $2 \%$ BSA. Samples were measured at a flow cytometer FACS Calibur ${ }^{\mathrm{TM}}$ (BD Biosciences, Franklin Lakes, NJ, USA) at the excitation/emission wavelength $488 / 530 \mathrm{~nm}$ (channel FL-1). Geometric means were calculated using CellQuest ${ }^{\mathrm{TM}}$ Pro.

\subsection{Statistical Methods}

Statistical analysis was done using GraphPad Prism software version 4.03 (GraphPad Software Inc., La Jolla, CA, USA). To determine statistical significance one-way analysis of variance (ANOVA) with Bonferroni post-test was performed. Asterisks indicate statistically significant differences $(* p<0.05$; $* * p<0.01 ; * * * p<0.001)$. Figures with bar graphs represent mean $\pm \mathrm{SD}$ of at least three independent experiments.

\section{Conclusions}

To the best of our knowledge this study shows for the first time the absence of a direct role of the main physiological resveratrol metabolites on eNOS enzyme activity, NO release and intracellular ROS production in endothelial cells. Further studies are necessary to evaluate a possible influence of resveratrol metabolites not tested here, such as dihydro-resveratrol and its glucuronic and sulfated derivatives, which have recently been identified in rat liver and adipose tissue [42] and the potential synergy of combinations of resveratrol and the single metabolites. Back-conversion of resveratrol metabolites to resveratrol in the target tissue would also account for the lack of activity of metabolites observed in this study. Another explanation for the lack of activity of the resveratrol metabolites could be that endothelial function is influenced by a here not investigated pathway, or that the applied in vitro system is too artificial for the complex situation in vivo.

\section{Acknowledgments}

The work was funded in part by the Austrian Science Fund (FWF): P18982-B17 and P23317-B11 as well as the University of Vienna via the initiative group BioProMoTION.

\section{Author Contributions}

A.L. and D.S. designed and performed experiments as well as analyzed data; A.L. drafted the manuscript; K.S. synthesized resveratrol glucuronides and performed experiments; M.P. synthesized resveratrol sulfates; V.M.D., E.H.H. and V.S. conceived and supervised the study. All the authors read, commented on and approved the final manuscript.

\section{Conflicts of Interest}

The authors declare no conflict of interest. 


\section{References}

1. Forstermann, U.; Munzel, T. Endothelial nitric oxide synthase in vascular disease: From marvel to menace. Circulation 2006, 113, 1708-1714.

2. Davignon, J.; Ganz, P. Role of endothelial dysfunction in atherosclerosis. Circulation 2004, 109 (Suppl. 1), III-27-III-32.

3. Baur, J.A.; Sinclair, D.A. Therapeutic potential of resveratrol: The in vivo evidence. Nat. Rev. Drug Discov. 2006, 5, 493-506.

4. Pervaiz, S.; Holme, A.L. Resveratrol: Its biologic targets and functional activity. Antioxid. Redox Sign. 2009, 11, 2851-2897.

5. Schmitt, C.A.; Heiss, E.H.; Dirsch, V.M. Effect of resveratrol on endothelial cell function: Molecular mechanisms. Biofactors 2010, 36, 342-349.

6. Xu, Q.; Hao, X.; Yang, Q.; Si, L. Resveratrol prevents hyperglycemia-induced endothelial dysfunction via activation of adenosine monophosphate-activated protein kinase. Biochem. Biophys. Res. Commun. 2009, 388, 389-394.

7. Klinge, C.M.; Blankenship, K.A.; Risinger, K.E.; Bhatnagar, S.; Noisin, E.L.; Sumanasekera, W.K.; Zhao, L.; Brey, D.M.; Keynton, R.S. Resveratrol and estradiol rapidly activate MAPK signaling through estrogen receptors alpha and beta in endothelial cells. J. Biol. Chem. 2005, 280, 7460-7468.

8. Mattagajasingh, I.; Kim, C.S.; Naqvi, A.; Yamamori, T.; Hoffman, T.A.; Jung, S.B.; DeRicco, J.; Kasuno, K.; Irani, K. SIRT1 promotes endothelium-dependent vascular relaxation by activating endothelial nitric oxide synthase. Proc. Natl. Acad. Sci. USA 2007, 104, 14855-14860.

9. Arunachalam, G.; Yao, H.; Sundar, I.K.; Caito, S.; Rahman, I. SIRT1 regulates oxidant- and cigarette smoke-induced eNOS acetylation in endothelial cells: Role of resveratrol. Biochem. Biophys. Res. Commun. 2010, 393, 66-72.

10. Wallerath, T.; Deckert, G.; Ternes, T.; Anderson, H.; Li, H.; Witte, K.; Forstermann, U. Resveratrol, a polyphenolic phytoalexin present in red wine, enhances expression and activity of endothelial nitric oxide synthase. Circulation 2002, 106, 1652-1658.

11. Hsieh, T.C.; Juan, G.; Darzynkiewicz, Z.; Wu, J.M. Resveratrol increases nitric oxide synthase, induces accumulation of p53 and p21(WAF1/CIP1), and suppresses cultured bovine pulmonary artery endothelial cell proliferation by perturbing progression through S and G2. Cancer Res. 1999, 59, 2596-2601.

12. Leikert, J.F.; Rathel, T.R.; Wohlfart, P.; Cheynier, V.; Vollmar, A.M.; Dirsch, V.M. Red wine polyphenols enhance endothelial nitric oxide synthase expression and subsequent nitric oxide release from endothelial cells. Circulation 2002, 106, 1614-1617.

13. Nicholson, S.K.; Tucker, G.A.; Brameld, J.M. Effects of dietary polyphenols on gene expression in human vascular endothelial cells. Proc. Nutr. Soc. 2008, 67, 42-47.

14. Schmitt, C.A.; Dirsch, V.M. Modulation of endothelial nitric oxide by plant-derived products. Nitric Oxide 2009, 21, 77-91.

15. Pearson, K.J.; Baur, J.A.; Lewis, K.N.; Peshkin, L.; Price, N.L.; Labinskyy, N.; Swindell, W.R.; Kamara, D.; Minor, R.K.; Perez, E.; et al. Resveratrol delays age-related deterioration and mimics transcriptional aspects of dietary restriction without extending life span. Cell Metab. 2008, 8, 157-168. 
16. Rush, J.W.; Quadrilatero, J.; Levy, A.S.; Ford, R.J. Chronic resveratrol enhances endothelium-dependent relaxation but does not alter eNOS levels in aorta of spontaneously hypertensive rats. Exp. Biol. Med. (Maywood) 2007, 232, 814-822.

17. Walle, T. Bioavailability of resveratrol. Ann. N. Y. Acad. Sci. 2011, 1215, 9-15.

18. Wenzel, E.; Soldo, T.; Erbersdobler, H.; Somoza, V. Bioactivity and metabolism of trans-resveratrol orally administered to Wistar rats. Mol. Nutr. Food Res. 2005, 49, 482-494.

19. Wenzel, E.; Somoza, V. Metabolism and bioavailability of trans-resveratrol. Mol. Nutr. Food Res. 2005, 49, 472-481.

20. Walle, T.; Hsieh, F.; DeLegge, M.H.; Oatis, J.E., Jr.; Walle, U.K. High absorption but very low bioavailability of oral resveratrol in humans. Drug Metab. Dispos. 2004, 32, 1377-1382.

21. Delmas, D.; Aires, V.; Limagne, E.; Dutartre, P.; Mazue, F.; Ghiringhelli, F.; Latruffe, N. Transport, stability, and biological activity of resveratrol. Ann. N. Y. Acad. Sci. 2011, 1215, 48-59.

22. Patel, K.R.; Andreadi, C.; Britton, R.G.; Horner-Glister, E.; Karmokar, A.; Sale, S.; Brown, V.A.; Brenner, D.E.; Singh, R.; Steward, W.P.; et al. Sulfate metabolites provide an intracellular pool for resveratrol generation and induce autophagy with senescence. Sci. Transl. Med. 2013, 5, doi:10.1126/scitranslmed.3005870.

23. Lasa, A.; Churruca, I.; Eseberri, I.; Andres-Lacueva, C.; Portillo, M.P. Delipidating effect of resveratrol metabolites in 3T3-L1 adipocytes. Mol. Nutr. Food Res. 2012, 56, 1559-1568.

24. Eseberri, I.; Lasa, A.; Churruca, I.; Portillo, M.P. Resveratrol metabolites modify adipokine expression and secretion in 3T3-L1 pre-adipocytes and mature adipocytes. PLoS one 2013, 8, e63918.

25. Walker, J.; Schueller, K.; Schaefer, L.M.; Pignitter, M.; Esefelder, L.; Somoza, V. Resveratrol and its metabolites inhibit pro-inflammatory effects of lipopolysaccharides in U-937 macrophages in plasma-representative concentrations. Food Funct. 2013, 5, 74-84.

26. Calamini, B.; Ratia, K.; Malkowski, M.G.; Cuendet, M.; Pezzuto, J.M.; Santarsiero, B.D.; Mesecar, A.D. Pleiotropic mechanisms facilitated by resveratrol and its metabolites. Biochem. J. 2010, 429, 273-282.

27. Aires, V.; Limagne, E.; Cotte, A.K.; Latruffe, N.; Ghiringhelli, F.; Delmas, D. Resveratrol metabolites inhibit human metastatic colon cancer cells progression and synergize with chemotherapeutic drugs to induce cell death. Mol. Nutr. Food Res. 2013, 57, 1170-1181.

28. Polycarpou, E.; Meira, L.B.; Carrington, S.; Tyrrell, E.; Modjtahedi, H.; Carew, M.A. Resveratrol 3-O-d-glucuronide and resveratrol 4'-O-d-glucuronide inhibit colon cancer cell growth: Evidence for a role of A3 adenosine receptors, cyclin D1 depletion, and G1 cell cycle arrest. Mol. Nutr. Food Res. 2013, 57, 1708-1717.

29. Wallerath, T.; Li, H.; Godtel-Ambrust, U.; Schwarz, P.M.; Forstermann, U. A blend of polyphenolic compounds explains the stimulatory effect of red wine on human endothelial NO synthase. Nitric Oxide 2005, 12, 97-104.

30. Klinge, C.M.; Wickramasinghe, N.S.; Ivanova, M.M.; Dougherty, S.M. Resveratrol stimulates nitric oxide production by increasing estrogen receptor alpha-Src-caveolin-1 interaction and phosphorylation in human umbilical vein endothelial cells. FASEB J. 2008, 22, 2185-2197.

31. Gualdoni, G.A.; Kovarik, J.J.; Hofer, J.; Dose, F.; Pignitter, M.; Doberer, D.; Steinberger, P.; Somoza, V.; Wolzt, M.; Zlabinger, G.J. Resveratrol enhances TNF-alpha production in human monocytes upon bacterial stimulation. Biochim. Biophys. Acta 2014, 1840, 95-105. 
32. Leonard, S.S.; Xia, C.; Jiang, B.H.; Stinefelt, B.; Klandorf, H.; Harris, G.K.; Shi, X. Resveratrol scavenges reactive oxygen species and effects radical-induced cellular responses. Biochem. Biophys. Res. Commun. 2003, 309, 1017-1026.

33. Spanier, G.; Xu, H.; Xia, N.; Tobias, S.; Deng, S.; Wojnowski, L.; Forstermann, U.; Li, H. Resveratrol reduces endothelial oxidative stress by modulating the gene expression of superoxide dismutase 1 (SOD1), glutathione peroxidase 1 (GPx1) and NADPH oxidase subunit (Nox4). J. Physiol. Pharmacol. 2009, 60 (Suppl. 4), 111-116.

34. Kaga, S.; Zhan, L.; Matsumoto, M.; Maulik, N. Resveratrol enhances neovascularization in the infarcted rat myocardium through the induction of thioredoxin-1, heme oxygenase-1 and vascular endothelial growth factor. J. Mol. Cell. Cardiol. 2005, 39, 813-822.

35. Pasciu, V.; Posadino, A.M.; Cossu, A.; Sanna, B.; Tadolini, B.; Gaspa, L.; Marchisio, A.; Dessole, S.; Capobianco, G.; Pintus, G. Akt downregulation by flavin oxidase-induced ROS generation mediates dose-dependent endothelial cell damage elicited by natural antioxidants. Toxicol. Sci. 2010, 114, 101-112.

36. Schilder, Y.D.; Heiss, E.H.; Schachner, D.; Ziegler, J.; Reznicek, G.; Sorescu, D.; Dirsch, V.M. NADPH oxidases 1 and 4 mediate cellular senescence induced by resveratrol in human endothelial cells. Free Radic. Biol. Med. 2009, 46, 1598-1606.

37. Gadacha, W.; Ben-Attia, M.; Bonnefont-Rousselot, D.; Aouani, E.; Ghanem-Boughanmi, N.; Touitou, Y. Resveratrol opposite effects on rat tissue lipoperoxidation: Pro-oxidant during day-time and antioxidant at night. Redox Rep. 2009, 14, 154-158.

38. Edgell, C.J.; McDonald, C.C.; Graham, J.B. Permanent cell line expressing human factor VIII-related antigen established by hybridization. Proc. Natl. Acad. Sci. USA 1983, 80, 3734-3737.

39. Schmitt, C.A.; Handler, N.; Heiss, E.H.; Erker, T.; Dirsch, V.M. No evidence for modulation of endothelial nitric oxide synthase by the olive oil polyphenol hydroxytyrosol in human endothelial cells. Atherosclerosis 2007, 195, e58-e64.

40. O'Brien, J.; Wilson, I.; Orton, T.; Pognan, F. Investigation of the Alamar Blue (resazurin) fluorescent dye for the assessment of mammalian cell cytotoxicity. Eur. J. Biochem. 2000, 267, 5421-5426.

41. Long, L.H.; Clement, M.V.; Halliwell, B. Artifacts in cell culture: Rapid generation of hydrogen peroxide on addition of (-)-epigallocatechin, (-)-epigallocatechin gallate, $(+)$-catechin, and quercetin to commonly used cell culture media. Biochem. Biophys. Res. Commun. 2000, 273, 50-53.

42. Andres-Lacueva, C.; Macarulla, M.T.; Rotches-Ribalta, M.; Boto-Ordonez, M.; Urpi-Sarda, M.; Rodriguez, V.M.; Portillo, M.P. Distribution of resveratrol metabolites in liver, adipose tissue, and skeletal muscle in rats fed different doses of this polyphenol. J. Agric. Food Chem. 2012, 60, 4833-4840.

Sample Availability: Not available.

(C) 2014 by the authors; licensee MDPI, Basel, Switzerland. This article is an open access article distributed under the terms and conditions of the Creative Commons Attribution license (http://creativecommons.org/licenses/by/4.0/). 